\title{
Lower urinary tract symptoms in men: challenges to early hospital presentation in a resource-poor health system
}

\author{
Ikenna I. Nnabugwu ${ }^{1^{*}}$ (D), ljeoma L. Okoronkwo² and Chinwe A. Nnabugwu²
}

\begin{abstract}
Background: The point at which men seek medical care for lower urinary tract symptoms (LUTS) varies between individuals. Presentation to hospital with complications beyond LUTS appears prevalent in our setting. The aim of this survey is to assess from the community perspective in southeast Nigeria, the challenges to early presentation for medical evaluation for LUTS by men.

Methods: A questionnaire-based cross-sectional survey of randomly-selected men $\geq 40$ years. The questionnaire captured respondent's age; presence, duration and severity of LUTS; access to health information; wealth-index; and when (and why) medical care for LUTS was sought. Analysis was with SPSS ${ }^{\oplus}$ version 20.

Results: In all, responses from 1319 men (mean age 54.2 \pm 10.2 years) are analysed. Of these, 267 report LUTS: $58.4 \%$ (156) report moderate to severe LUTS and 51.7\% (138) are yet to seek medical care. As regards seeking medical care, all the men reporting LUTS of 3 months, 35.7\% of 126 men reporting moderate LUTS, and 20.0\% of 30 men reporting severe LUTS are yet to seek medical care. LUTS being non-bothersome (not financial constraint) is the most prevalent reason for not seeking medical care early. Delay is encouraged by limited access to health information (OR 3.10; $p<0.001$ ), but discouraged by literacy (OR 0.86; $p<0.001)$ and aging (OR 0.93; $p=0.002$ ).

Conclusion: From the community perspective, the prevalent challenge to seeking medical care for LUTS early is absence of bother. Empowering men through formal education and researched health information will influence positively the time that LUTS in men is appreciated as bothersome.
\end{abstract}

Keywords: LUTS, Men, Medical-care, Challenges, Delay

\section{Background}

Lower urinary tract symptoms (LUTS) are a set of symptoms that usually indicate that there is dysfunction in the storage and controlled evacuation of urine from the urinary bladder [1]. These symptoms can occur in any age group, but the reasons for the symptoms vary from age to age and from one gender to the other [2]. Irrespective of the primary diagnosis, it is suspected

\footnotetext{
* Correspondence: ikenna.nnabugwu@unn.edu.ng

1 Department of Surgery, College of Medicine, University of Nigeria Ituku-Ozalla, Enugu PMB 01129, Nigeria

Full list of author information is available at the end of the article
}

that LUTS could have a common pathway [3]. The occurrence of any or some of these symptoms is an indication that there is altered bladder compliance, altered infravesical resistance, increased flow of urine into the bladder, or a combination of these in varying proportions [4]. LUTS may vary from sudden onset transient LUTS, to insidious onset progressive LUTS [5]. In men who are 40 years of age and older, common disease conditions associated with insidious onset progressive LUTS include enlarging benign and malignant prostates, chronic prostatitis, urethral stricture disorders, neoplastic diseases of the urinary bladder,

C C The Author(s). 2020 Open Access This article is licensed under a Creative Commons Attribution 4.0 International License, which permits use, sharing, adaptation, distribution and reproduction in any medium or format, as long as you give appropriate credit to the original author(s) and the source, provide a link to the Creative Commons licence, and indicate if changes were made. The images or other third party material in this article are included in the article's Creative Commons licence, unless indicated otherwise in a credit line to the material. If material is not included in the article's Creative Commons licence and your intended use is not permitted by statutory regulation or exceeds the permitted use, you will need to obtain permission directly from the copyright holder. To view a copy of this licence, visit http://creativecommons.org/licenses/by/4.0/ The Creative Commons Public Domain Dedication waiver (http://creativecommons.org/publicdomain/zero/1.0/) applies to the data made available in this article, unless otherwise stated in a credit line to the data. 
neurogenic bladder disorders, diuresis-causing disorders and many more [6-8]. Some of these disease conditions have attendant grave consequences if not promptly and appropriately addressed medically [9].

Men experiencing LUTS seek medical care at varying points in symptom progression [10]. A number of individual constitutional, social and economic factors, interacting with each other, have been documented to influence the intention to seek medical care: some of them are cultural belief and practice, self-perceived aging [11], literacy level [12], poor finances and accessibility of medical care especially in the absence of robust health insurance [13], and exposure to health information [14].

Left unattended, most of the disease conditions resulting in progressive LUTS and worsening bladder outlet obstruction have increasing risk of life-threatening complications such as obstructive nephropathy, septicaemia, acute urinary retention, and so on [15]. In fact, some of these disease conditions such as prostate and bladder cancers are only curable in the early stages of the diseases, when LUTS alone may be the pointer to the possibility of the diagnosis. Yet allegedly, many men express challenges to appropriate medical care at this early phase of disease evolution [16].

In a typical low-income country with poor health insurance coverage, hospital-based studies report that men diagnosed of benign prostate enlargement (BPE), prostate cancer, bladder cancer, and other disease conditions whose early clinical features are LUTS predominantly present to appropriate hospitals late with complications beyond LUTS [17]. On the other hand, in other climes it has been documented that there is more to seeking medical care for LUTS by men than providing free healthcare services [18]. LUTS of varying severity and duration are considered nonbothersome by men. In addition, men feel embarrassed discussing their LUTS with someone else including medical care providers [19]. The prevalent challenge to early presentation with LUTS in lowincome setting may not be financial constraints. The aim of this study therefore is to identify, from the community perspective, the challenges to early presentation to appropriate medical care for LUTS in men. This knowledge will help focus on the right strategies towards improving on early presentation for medical care.

\section{Methods}

This interviewer-assisted, questionnaire-based crosssectional survey was conducted from March 5th to May 25th, 2018 in Enugu, southeast Nigeria. From the 2006 population figures, Enugu has an estimated population of 983,000 persons, $22.0 \%$ of which are men who are 40 years and above [20].
The survey questionnaire which was administered by pre-tutored trainee Urologists and intern doctors, captured respondent's age and presence or not of LUTS. Where LUTS were reported, the duration of the reported LUTS was ascertained. In addition, the questionnaire assessed respondent's attitude to seeking medical care early using a 4-point Likert scale on 5 question stems as adapted from Davis et al. [21] The severity of LUTS and the quality of life (QoL) due to the reported LUTS were assessed using validated International Prostate Symptom Score (IPSS) chart [22]. For respondents that had sought medical care for the reported LUTS, the duration of LUTS before medical care was sought as well as the reason for seeking medical care was determined. The nature of medical care sought in the first instance was noted.

Access to possible health information on LUTS was captured in terms of discussions on LUTS with family and peers as well as exposure to conventional media and internet health broadcasts and write ups.

Finally, household living conditions and durable assets adapted from Nigeria-General Household Survey, Panel 2015-2016, Wave 3 [23], were assessed for the purpose of creating respondent's wealth index. Reliability test yielded Cronbach's $\alpha=0.735$ for the wealth index variables.

The sample size as worked out using the formula $n$ $=\frac{Z^{2} P(1-P)}{d^{2}}$ is 372 subjects; where $P$ is 0.591 [24], $Z$ is 1.96 and $d$ is 0.05 . As reported in Nnabugwu et al., (2019) [25] 3 of 9 settlement clusters were randomly selected in Enugu for the study. Within the clusters, the study participants were selected through a systematic random sampling technique of 1 in every 3 eligible men. To be included in the study were men 40 years and older and dwelling within the clusters. Written informed consent was obtained from each eligible participant before inclusion.

Simple frequency was used to determine prevalence of LUTS and nature of medical care sought firstly. Arithmetic mean on compute variable was used to differentiate respondents with good attitude from those with poor attitude to seeking medical care based on responses from the Likert questions focusing on attitude to seeking medical care. Principal Component Analysis (PCA) was used to create wealth indices using the data on household durable assets and living conditions. PCA was also used to create health information indices using responses on possible sources of health information on LUTS. Logistic Regression Analysis was used to evaluate factors that influence duration from onset of LUTS to seeking medical care. Significance was set at $p<0.05$. All analyses were done with SPSS $^{\circ}$ version 20. The University of Nigeria Teaching Hospital Bioethics Committee approved of the study. 


\section{Results}

Figure 1 shows the pathway to patient recruitment in this survey. One thousand three hundred and nineteen (1319) duly completed questionnaires out of 1337 were returned for analysis. The socio-demographic characteristics of these respondents are shown in Table 1.

Majority of the respondents are between 40 and 59 years of age' acquired more than 6 years of formal education and reported no lower urinary tract symptoms.

Two hundred and sixty-seven (267) of the 1319 respondents report at least one lower urinary tract symptom which gives overall LUTS prevalence rate of $20.2 \%$. Nocturia at a rate of $19.9 \%$ is the most prevalent lower urinary tract symptom. Within the subset of men reporting LUTS $(N=267)$ nocturia is the earliest symptom reportedly noticed (35.2\%). The prevalence of LUTS increases with increasing decade of life from $10.2 \%$ in the 5 th decade of life to $70.0 \%$ in the 9th decade. Similarly, the severity of LUTS determined using IPSS worsens with increasing decade of life $\left(x^{2} 152.9\right.$; df 15; $p<0.001)$.

Respondents experiencing LUTS report various durations of LUTS and those who had sought medical care report various durations from onset of symptom(s) to seeking medical care. These are shown in Table 2.

Table 2 shows that as symptoms persist or progress, increasing number of men experiencing LUTS reportedly sought medical care.

One hundred and forty-two of the 267 that reported LUTS (53.2\%) demonstrate good attitude to early medical care. Eighty-seven of the 111 respondents reporting mild LUTS (78.4\%) are yet to seek medical care; 45 of 126 reporting moderate LUTS (35.7\%) are yet to seek medical care while 6 of 30 reporting severe LUTS (20.0\%) are yet to seek medical care. Twenty-five of 94 respondents $(26.6 \%)$ reporting symptoms of more than 2 years, which has progressed to moderate to severe LUTS, are yet to seek medical care. Some of the reasons for not seeking medical care yet are shown in Table 3.

From Table 3, LUTS considered non-bothersome is the most prevalent reason for not seeking medical care for LUTS of various durations.

On the other hand, of these 267 respondents reporting LUTS, 129 had sought medical care from different care providers. Figure 2 is the frequency distribution of the types of care providers sought in the first instance by these respondents. Some of the reasons for seeking medical care when medical care was sought include: worsening of symptoms (38.0\%), persistence of symptoms (26.4\%), fear of something worse $(18.6 \%)$, pressure from family and friends (14.0\%) and others including loss of erection (3.1\%).

From this figure, most of the respondents that sought medical care reportedly sought the services of orthodox medical doctors firstly.

The variables that influence the decision to seek medical care at the time medical care was sought were subjected to ordinal logistic regression analysis and the result is shown in Table 4.

From Table 4, age and formal educational status of respondent, severity and duration of LUTS, as well as health information index of respondent significantly

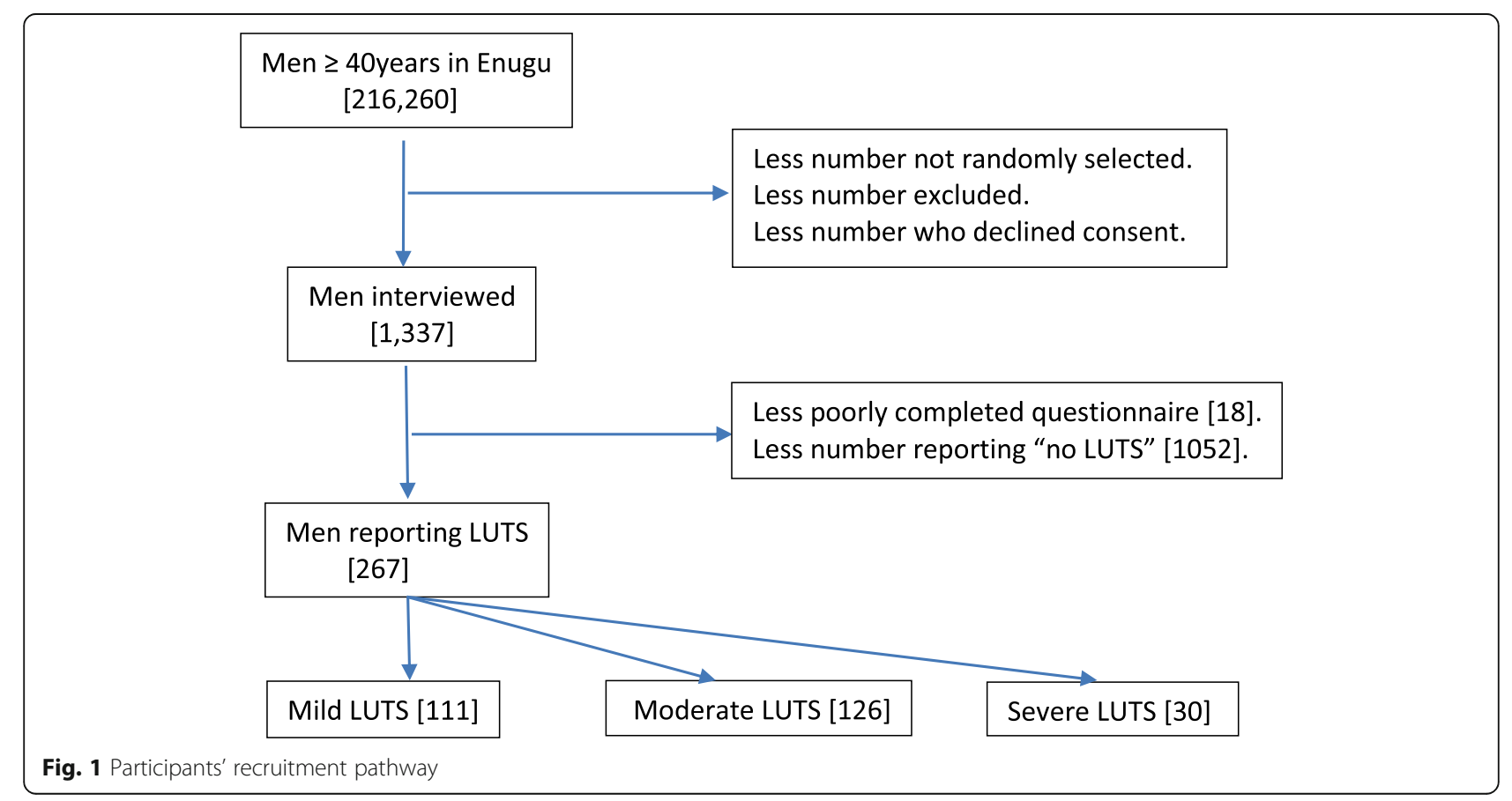


Table 1 Socio-demographic characteristics of respondents

\begin{tabular}{|c|c|c|}
\hline Variables & & Frequency (\%) \\
\hline \multirow[t]{6}{*}{ Age of Respondents (years) } & $40-49$ & $500(37.9 \%)$ \\
\hline & $50-59$ & $420(31.8 \%)$ \\
\hline & $60-69$ & $277(21.0 \%)$ \\
\hline & $70-79$ & $110(8.3 \%)$ \\
\hline & $80-89$ & $10(0.8 \%)$ \\
\hline & $90-99$ & $2(0.2 \%)$ \\
\hline Mean Age of Respondents (years) & $54.2 \pm 10.2$ & \\
\hline \multirow[t]{2}{*}{ Duration of Formal Education (years) } & $\leq 6$ & $466(35.3 \%)$ \\
\hline & $>6$ & $853(64.7 \%)$ \\
\hline Mean Duration Formal Education (years) & $10.5 \pm 5.3$ & \\
\hline \multirow[t]{4}{*}{ Years in Marriage } & Not Married & $27(2.1 \%)$ \\
\hline & $\leq 10$ years & $350(26.5 \%)$ \\
\hline & $11-20$ years & $442(33.5 \%)$ \\
\hline & $>20$ years & $500(37.9 \%)$ \\
\hline \multirow[t]{3}{*}{ Number of Siblings } & None & $14(1.1 \%)$ \\
\hline & $1-5$ & $718(54.4 \%)$ \\
\hline & $>5$ & $587(44.5 \%)$ \\
\hline Any LUTS & & $267(20.2 \%)$ \\
\hline Mild LUTS & $($ IPSS $\leq 7)$ & $111(8.4 \%)$ \\
\hline Moderate LUTS & (IPSS 8-19) & $126(9.6 \%)$ \\
\hline Severe LUTS & $($ IPSS $\geq 20)$ & $30(2.3 \%)$ \\
\hline
\end{tabular}

[LUTS lower urinary tract symptoms]

influence the time in the course of LUTS that medical care is sought.

\section{Discussion}

At an overall LUTS prevalence rate of $20.2 \%$ and moderate to severe LUTS prevalence rate of $11.9 \%$ (Table 1), LUTS in men deserve some emphasis in discussions of men's health [25]. This is particularly important realizing that $51.7 \%$ of all men reporting any lower urinary tract symptom from this survey are yet to seek medical care, and that $32.7 \%$ of men reporting moderate to severe symptoms are as well yet to seek medical care. These findings are similar to findings from other studies [24, 26, 27] and are worrisome because of the health implications of seeking medical care late in this health disorder [17]. It is obvious that some of the primary disease conditions resulting in LUTS have poor prognosis with late presentations to medical care $[15,16]$. It is therefore quite disturbing that many of these men (Table 2) experience these lower urinary symptoms for years without seeking medical care.

The explanation for this care seeking behaviour in this cohort of men could be that there is some degree of aversion for orthodox medical care generally, or for medical care for LUTS specifically. However, a good

Table 2 Duration from onset of LUTS to seeking medical care for the reported LUTS

\begin{tabular}{|c|c|c|c|c|}
\hline \multirow[t]{2}{*}{ Duration of LUTS } & \multirow[t]{2}{*}{ Yet to seek care } & \multicolumn{3}{|c|}{ Sought Medical Care } \\
\hline & & Within 3mths & In 4-12mths & After $12 \mathrm{mths}$ \\
\hline$\leq 3$ mths $(N=8)$ & $8(100 \%)$ & 0 & 0 & 0 \\
\hline $4-12$ mths $(N=51)$ & $25(49.0 \%)$ & $8(15.7 \%)$ & $16(31.4 \%)$ & 0 \\
\hline 13-24mths $(N=40)$ & $20(50.0 \%)$ & $1(2.5 \%)$ & $11(27.5 \%)$ & $8(20.0 \%)$ \\
\hline $25-60$ mths $(N=82)$ & $47(57.3 \%)$ & $1(1.2 \%)$ & $15(18.3 \%)$ & 19 (23.2\%) \\
\hline$>60 \mathrm{mths}(N=86)$ & $38(44.2 \%)$ & $3(3.5 \%)$ & $13(15.1 \%)$ & 32 (37.2\%) \\
\hline Total (267) & $138(51.7 \%)$ & $13(4.9 \%)$ & 55 (20.6\%) & 59 (22.1\%) \\
\hline
\end{tabular}

[mths months] 
Table 3 Reasons for not seeking medical care across the various durations of LUTS

\begin{tabular}{|c|c|c|c|c|c|}
\hline Duration of LUTS & Non-Bothersome & Poor Finance & Time Constraint & Advice & Others \\
\hline$\leq 3 \mathrm{mths}(N=8)$ & $4(50.0 \%)$ & $2(25.0 \%)$ & $2(25.0 \%)$ & 0 & 0 \\
\hline $4-12 \mathrm{mths}(N=25)$ & $20(80.0 \%)$ & $5(20.0 \%)$ & 0 & 0 & 0 \\
\hline 13-24mths $(N=20)$ & $13(65.0 \%)$ & $5(25.0 \%)$ & 0 & 0 & $2(10.0 \%$ \\
\hline $25-60$ mths $(N=47)$ & $34(72.3 \%)$ & $8(17.0 \%)$ & $2(4.3 \%)$ & $2(4.3 \%)$ & $1(2.1 \%)$ \\
\hline >60mths $(N=38)$ & $25(65.8 \%)$ & 11 (28.9\%) & 0 & $2(5.3 \%)$ & 0 \\
\hline Total (138) & $96(69.6 \%)$ & 31 (22.5\%) & $4(2.9 \%)$ & $4(2.9 \%)$ & $3(2.2 \%)$ \\
\hline
\end{tabular}

proportion (53.2\%) of these men reportedly demonstrate good attitude towards early medical care. In addition, when they decided to seek medical care for their LUTS, most (65.9\%; Fig. 2) of the respondents from this study consulted medical doctors firstly, demonstrating belief in conventional medical care. So, that these men appreciate the benefit in seeking medical care for health challenges from conventional medical care is not contestable. However, the trigger for seeking medical care for LUTS seems not to be just any lower urinary tract symptom. Curiously, this challenge to early medical care for LUTS seems not peculiar as seen from the review by Roehrborn et al. [28]

From the reasons given by respondents across all LUTS severity and symptom durations for seeking medical care belatedly, LUTS being non-bothersome ranks highest (Table 3) akin to the observation by Griffith et al. [19] So even in low-income economy with poor health insurance coverage, financial constraint does not represent the most prevalent reason for delay in seeking medical care for LUTS in men. To buttress this finding, this study also reveals that respondents' socio-economic status does not have any significant influence on when medical care is sought by men reporting LUTS (Table
4). It is only rational that one does not commit resources in terms of time and money in accessing care that is of doubtful utility. If LUTS are generally trivialized as part of aging in men, or attributed to some other factors [29], then men will fail to appreciate the utility in accessing medical care for LUTS being experienced. This stance needs to be actively corrected through enlightenment programmes since increasing level of formal education and higher exposure to health information are significantly associated with seeking medical care earlier for LUTS [30]. From this study, there is a 3.1 odd that a respondent of low health information index, due to minimal level of exposure to health information from lifestyle, will seek medical care belatedly compared to a respondent of high health information index (Table 4). Similarly, increase in level of formal education attained is associated with decrease in delay in seeking medical care for LUTS (OR 0.86; $p<0.001$; Table 4).

As regards age of respondent, the younger the respondent, the longer the delay in seeking medical care ( $p$ 0.002). This may be because the younger respondent tends to report milder LUTS, is likely to report less bother, and to attribute higher opportunity cost to seeking medical care. On the contrary, the older respondent

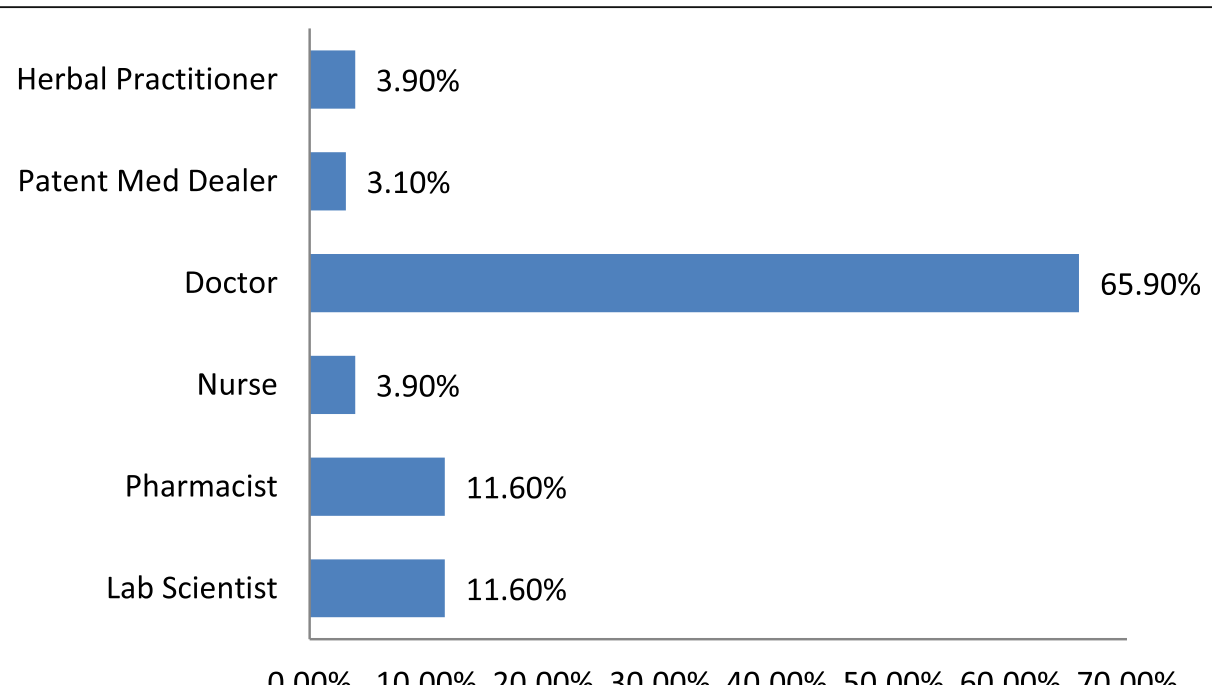

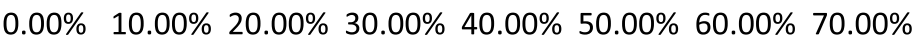

Fig. 2 Frequency distribution of care-providers accessed firstly by respondents who had accessed medical care for reported LUTS 
Table 4 Factors that influence the decision to seek medical care for LUTS

\begin{tabular}{lllll}
\hline Variable & Odds Ratio & $95 \% \mathrm{Cl}$ & $\boldsymbol{p}$-value \\
\hline Age & 0.93 & 0.90 & 0.98 & 0.002 \\
Education & 0.86 & 0.81 & 0.92 & $<0.001$ \\
Marriage & 1.03 & 1.00 & 1.06 & 0.080 \\
Siblings & 1.00 & 0.91 & 1.09 & 0.929 \\
Wealth Index 1 & 1.60 & 0.65 & 3.90 & 0.303 \\
Wealth Index 2 & 1.41 & 0.61 & 3.28 & 0.425 \\
Wealth Index 3 & 1.15 & 0.51 & 2.60 & 0.743 \\
Wealth Index 4 & 0.87 & 0.38 & 1.98 & 0.740 \\
Wealth Index 5 & & & & \\
$\quad \begin{array}{l}\text { Mild LUTS } \\
\quad \text { Moderate LUTS }\end{array}$ & 6.68 & 2.62 & 17.03 & $<0.001$ \\
Severe LUTS & 1.14 & 0.51 & 2.55 & 0.755 \\
$\quad$ LUTS 4-12 months & & & & \\
$\quad$ LUTS 13-24 months & 0.43 & 0.22 & 0.83 & 0.012 \\
LUTS > 24 months & 1.59 & 0.77 & 3.29 & 0.206 \\
$\quad$ Low Health Information Index & 3.10 & 1.79 & 5.38 & $<0.001$ \\
High Health Information Index & & & & \\
\hline
\end{tabular}

[LUTS lower urinary tract symptoms].

is, in addition, likely to be under more pressure from family and peers to seek medical care.

\section{Conclusion}

The observed key challenge with early presentation for medical care by men experiencing LUTS is that LUTS of various severity are considered non-bothersome. Financial constraint comes into play only when LUTS become bothersome. Wealth-index does not appear to influence when LUTS become bothersome, but older age, higher formal education and higher exposure to health information significantly do. Emphasis therefore should be on strategies designed to increase the knowledge base of men on the health implications of LUTS.

The implication therefore, is that empowering men in Nigeria through formal education and improved access to researched health information will influence positively the time that LUTS in men become bothersome. This in turn will help address the problem of late presentation for medical care with complications beyond LUTS.

\section{Supplementary information}

Supplementary information accompanies this paper at https://doi.org/10. 1186/s12894-020-00651-0.

Additional file 1.

\section{Abbreviations}

LUTS: Lower urinary tract symptoms; BPE: Benign prostate enlargement; QoL: Quality of life; PCA: Principal component analysis

\section{Acknowledgements}

We acknowledge Dr. Louis Okolie, Dr. Solomon Anyimba, Dr. Jude Ede, Dr. Ekeoma Nwosu, Dr. Uko Uko, Dr. Casmir Nnadi, Dr. Nonso Iwenofu, Dr. Pascal Maduabuchi, Dr. Wilson Onoh, Dr. Kingsley Onyia, Dr. Njideka Oragunye, Dr. Maxwell Isiwu, Dr. Chimuanya Mogbo, Dr. Hyginus Odoh, Dr. Pamela Okafor, Dr. Princewill Osueke, Dr. Arinze Onyia, Dr. Kingsley Bassey and Dr. Nwoku Amy, Dr. Chimuanya Mogbo, Dr. Bassey K Bassey, and Dr. Chinenye Eneh for their roles during data collection.

\section{Authors' contributions}

IIN contributed substantially in conception, design, data acquisition, analysis and interpretation of data, and in the drafting of the manuscript. ILO contributed substantially in design, analysis and interpretation of acquired data and revision of manuscript. CAN contributed substantially in conception, design, data acquisition, analysis and interpretation of acquired data, and drafting of manuscript. All Authors read and approved of the final version being submitted and agreed to be accountable for all parts of the research work.

\section{Funding}

No external source of funding.

\section{Availability of data and materials}

The datasets generated and analysed during the current study are available in the Mendeley data repository, [https://doi.org/10.17632/dgnnmwt752. 1\#file-849be15a-04ef-4c7b-ab06-6b1a74f05504].

Ethics approval and consent to participate

The University of Nigeria Teaching Hospital Bioethics Committee approved of this survey. Each participant gave a written consent.

Consent for publication

Not applicable.

\section{Competing interests}

This manuscript is adapted from the Project work of the corresponding author in partial fulfillment of the requirements for the award of MSc degree in Health Administration and Management. No other conflicts of interest declared.

\section{Author details}

'Department of Surgery, College of Medicine, University of Nigeria Ituku-Ozalla, Enugu PMB 01129, Nigeria. ${ }^{2}$ Department of Health Administration and Management, Faculty of Health Sciences and Technology, University of Nigeria Enugu Campus, Enugu, Nigeria.

Received: 30 January 2020 Accepted: 22 June 2020

Published online: 03 July 2020

\section{References}

1. Abdelmoteleb H, Jefferies ER, Drake MJ. Assessment and management of male lower urinary tract symptoms (LUTS). Int J Surg. 2016;25:164-71 https://doi.org/10.1016/j.ijsu.2015.11.043.

2. Hedlund P, Gratzke C. The endocannabinoid system - a target for treatment of LUTS. Nat Rev Urol. 2016;13(8):463-70 https://doi.org/10.1038/nrurol.2016.110.

3. Liu HT, Jiang YH, Kuo HC. Alteration of urethelial inflammation, apoptosis and junction protein in patients with various bladder conditions and storage bladder symptoms suggest common pathway involved in underlying pathophysiology. Low Urin Tract Symptoms. 2015;7(2):102-7 https://doi.org/10.1111/luts.12062.

4. Bellucci CHS, Ribeiro WO, Hemerly TS, de Bessa J Jr, Antunes AA, KRM L, Bruschini H, Srougi M, Gomes CM. Increased detrusor collagen is associated with detrusor overactivity and decreased bladder compliance in men with benign prostatic obstruction. Prostate Int. 2017;5(2):70-4 https://doi.org/10. 1016/j.pmil.2017.01.008.

5. Marshall LM, Holton KF, Parsons JK, Lapidus JA, Ramsey K, Barrett-Connor E. Osteoporotic fractures in men (MrOS) study group. Prostate Cancer Prostatic Dis. 2014;17(3):265-72 https://doi.org/10.1038/pcan.2014.22.

6. Brucker BM, Kalra S. Parkinson's disease and its effect on the lower urinary tract: evaluation of complications and treatment strategies. Urol Clin North Am. 2017;44(3):415-28 https://doi.org/10.1016/j.ucl.2017.04.008. 
7. Viuchoud C, Loughlin KR. Benign prostatic hyperplasia: epidemiology, economics and evaluation. Can J Urol. 2015;22(Suppl 1):1-6.

8. Hall SA, Chiu GR, Kaufman DW, Wittert GA, Link CL, McKinlay JB. Commonly used antihypertensives and lower urinary tract symptoms: results from the Boston area community health (BACH) survey. BJU Int. 2012;109(11):1676-84 https://doi.org/10.1111/j.1464-410X.2011.10593.x.

9. Weiss JP. Nocturia: focus on etiology and consequences. Rev Urol. 2012; 14(3-4):48-55 PMID: 23526404. PMCID: PMC3602727.

10. Thompson AE, Anisimowicz Y, Miedema B, Hogg W, Wodchis WP, AubreyBassler K. The influence of gender and other patient characteristics on health care-seeking behaviour: a QUALICOPC study. BMC Fam Pract. 2016; 17:38 https://doi.org/10.1186/s12875-016-0440-0.

11. Sun JK, Smith J. Self-perceptions of aging and perceived barriers to care: reasons for health care delay. Gerontologist. 2017;57(suppl_2):S216-26 https://doi.org/10.1093/geront/gnx014.

12. Stewart TS, Moodley J, Walter FM. Population risk factors for late-stage presentation of cervical cancer in sub-Saharan Africa. Cancer Epidemiol. 2018:53:81-92 https://doi.org/10.1016/j.canep.2018.01.014

13. Peng Y, Chang W, Zhou H, Hu H, Liang W. Factors associated with healthseeking behavior among migrant workers in Beijing, China. BMC Health Serv Res. 2010;10:69 https://doi.org/10.1186/1472-6963-10-69.

14. Rupert DJ, Gard Read J, Amoozegar JB, Moultrie RR, Taylor OM, O'Donoghue AC, Sullivan HW. Peer-generated health information: the role of online communities in patient and caregiver health decisions. J Health Commun, 2016;21(11):1187-97.

15. Speakman MJ, Cheng X. Management of the complications of $\mathrm{BPH} / \mathrm{BOO}$. Indian J Urol. 2014;30(2):208-13 https://doi.org/10.4103/0970-1591.127856.

16. Zargooshi J. Open prostatectomy for benign prostate hyperplasia: shortterm outcome in 3000 consecutive patients. Prostate Cancer Prostatic Dis. 2007;10(4):374-7.

17. Ugwumba FO, Ozoemena OF, Okoh AD, Echetabu KN, Mbadiwe OM. Transvesical prostatectomy in the management of benign prostatic hyperplasia in a developing country. Niger J Clin Pract. 2014;17(6):797-801 https://doi.org/10.4103/1119-3077.144402.

18. Lai UC, Wun YT, Luo TC, Pang SM. In a free healthcare system, why do men not consult for lower urinary tract symptoms (LUTS)? Asia Pac Fam Med. 2011;10(1):7 https://doi.org/10.1186/1447-056X-10-7.

19. Griffith JW, Messersmith EE, Gillespie BW, Wiseman JB, Flynn KE, Kirkali Z Kusek JW, Bavendam T, Cella D, Kreder K, Nero JJ, Corona ME, Bradley CS, Kenton KS, Helfand BT, Merion RM, Weinfurt KP, LURN Study Group. Reasons for seeking clinical care for lower urinary tract symptoms: a mixed methods study. J Urol. 2018;199(2):528-35 https://doi.org/10.1016/j.juro.2017.07.067.

20. Aliyu AA, Amadu L. Urbanization, cities, and health: the challenges to Nigeria -a review. Ann Afr Med. 2017;16(4):149-58 https://doi.org/10.4103/ aam.aam_1_17.

21. Davis L, Ajzen I, Saunders J, Williams T. The decision of African American students to complete high school: an application of the theory of planned behaviour. Working paper 02-5, Center for Social Development, Washington University U.S.A. 2002. www.gwbweb.wustl.edu/csd. Accessed 2 Apr 2018.

22. IPSS Form. Accessed from (www.urospec.com/uro/Forms/ipss.pdf) on 4 Dec 2017

23. Nigeria, UNDP. Human Development Report, Nigeria, 2008-2009. Abuja: United Nation Development Programme; 2009. Accessed from (www. nigerianstat.gov.ng) on 20 Feb 2018.

24. Ojewola RW, Oridota ES, Balogun OS, Ogundare EO, Alabi TO. Lower urinary tract symptoms: prevalence, perceptions, and healthcare-seeking behavior amongst Nigerian men. World J Mens Health. 2016;34(3):200-8 https://doi. org/10.5534/wjmh.2016.34.3.200.

25. Nnabugwu II, Ugwumba FO, Udeh El, Anyimba SK, Okolie LT. The relationship between prevalence and severity of lower urinary tract symptoms (LUTS), and body mass index and mid-abdominal circumference in men in resource-poor community in Southeast Nigeria: a cross-sectional survey. BMC Urol. 2019;19(1):15 https://doi.org/10.1186/s12894-019-0444-x.

26. Lammers HA, van Wijnhoven R, Teunissen TA, Harmsen S, Lagro-Janssen AL. Why do men suffering from LUTS seek primary medical care? A qualitative study. J Eval Clin Pract. 2015;21(5):931-6 https://doi.org/10.1111/jep.12407.

27. Stothers L, Macnab AJ, Bajunirwe F, Mutabazi S, Berkowitz J. Associations between the severity of obstructive lower urinary tract symptoms and care seeking behaviour in rural Africa: a cross sectional survey from Uganda. PLoS One. 2017;12(3):e0173631 https://doi.org/10.1371/journal.pone. 0173631.
28. Roehrborn CG, Miner MM, Sadovsky R. Over-the-counter medication availability could augment self-management of male lower urinary tract symptoms. Postgrad Med. 2018:1-9 https://doi.org/10.1080/00325481.2018. 1487238.

29. Siu JY. Imprisoned in the cultural stereotypes of overactive bladder: cultural meanings of disease and sick role adaptation in Hong Kong. Nurs Res. 2016; 65(5):352-61 https://doi.org/10.1097/NNR.0000000000000177.

30. Houle J, Meunier S, Coulome S, Mercerat C, Gaboury I, Tremblay G, de Montigny F, Cloutier L, Roy B, Auger N, Lavoie B. Peer positive social control and men's health-promoting behaviors. Am J Mens Health. 2017;11(5):156979 https://doi.org/10.1177/1557988317711605.

\section{Publisher's Note}

Springer Nature remains neutral with regard to jurisdictional claims in published maps and institutional affiliations.
Ready to submit your research? Choose BMC and benefit from:

- fast, convenient online submission

- thorough peer review by experienced researchers in your field

- rapid publication on acceptance

- support for research data, including large and complex data types

- gold Open Access which fosters wider collaboration and increased citations

- maximum visibility for your research: over $100 \mathrm{M}$ website views per year

At BMC, research is always in progress.

Learn more biomedcentral.com/submissions 